\title{
DIPLOMACIA CIENTÍFICA E DIPLOMACIA DA INOVAÇÃO: UMA REVISÃO SISTEMÁTICA DE LITERATURA SOBRE A PERSPECTIVA BRASILEIRA
}

\section{Science Diplomacy and Innovation Diplomacy: a systematic literature review on the Brazilian perspective}

\section{Introdução}

A Diplomacia Científica (DC), cujo campo de estudo está em consolidação, aborda o papel da Ciência, Tecnologia e Inovação (CT\&I) nas Relações Internacionais, sobretudo como meio de cooperação entre os países. Em razão de a CT\&I estar inserida em dinâmicas sociais, políticas e econômicas, essa área tem característica objetiva ou "instrumentalizada" na arena política e social (WEISS, 2005, p. 297). Isso conduz à utilização da CT\&I como instrumento de diplomacia mediante a DC, apresentada como um elo entre o mundo político e o mundo da ciência. No cenário contemporâneo de globalização econômica e de contundentes desafios sociais, a DC possibilita o desenvolvimento de respostas por meio de uma cooperação científica atrelada à política externa ${ }^{3}$ dos países.

Neste artigo, exploraremos a problemática da difusão do conceito brasileiro de "Diplomacia da Inovação" (DI) na academia4 . É possível identificar o conceito de DI como elaborado e desenvolvido em trabalhos vinculados ao Ministério das Relações Exteriores (MRE) do Brasil, como àqueles sob autoria de

\footnotetext{
${ }^{1}$ Doutoranda em Relações Internacionais pelo Programa de Pós-Graduação em Relações Internacionais (PPGRI) da Universidade Federal de Santa Catarina (UFSC). Mestra em Ciência Política, pelo Programa de Pós-Graduação em Ciência Política da Universidade Federal do Rio Grande do Sul (UFRGS). Graduada em Ciências Jurídicas e Sociais pela Pontifícia Universidade Católica do Rio Grande do Sul (PUC-RS). Email: roanunciato@gmail.com

${ }^{2}$ Mestranda no Programa de Pós-Graduação em Relações Internacionais (PPGRI) da Universidade Federal de Santa Catarina (UFSC). Bacharela em Relações Internacionais pela Universidade do Vale do Itajaí (UNIVALI). Email: barbaramarques713@gmail.com

${ }^{3}$ Entende-se por política externa as “Ações expressas na forma de metas definidas explicitamente, compromissos e/ou diretrizes, realizadas por representantes governamentais, agindo em nome de suas comunidades soberanas, são direcionadas no sentido de alcançar objetivos, condições e atores que eles desejam influenciar e que estejam além da legitimidade de seu território" (CARLSNAES et al., 2000, p. 335, tradução nossa).

${ }^{4}$ A proposta deste artigo é dimensionar a difusão do conceito de Diplomacia da Inovação na academia, isto é, em publicações científicas, por isso, não será testada a aplicabilidade do conceito como ferramenta da Política Externa Brasileira. Ademais, a metodologia utilizada não seria apropriada para tal abordagem.
} 
Ademar Seabra da Cruz Junior, e em publicações científicas de outros funcionários estatais, como os pertencentes à Empresa Brasileira de Pesquisa Agropecuária (Embrapa) e ao Ministério da Ciência, Tecnologia, Inovações e Comunicações (MCTIC).

A DI apresentar-se-ia como proposta e via de inserção do Brasil no contexto internacional da DC, dentro do panorama da pesquisa acadêmica em temas de cooperação internacional em CT\&I. Ressalta-se que a criação do termo teria por escopo transmitir uma perspectiva brasileira no cenário internacional de cooperação em CT\&I, distinta da preconizada pela DC. E, por isso, a escolha da nomenclatura de DI para o processo de cooperação científica, tecnológica e de inovação poderia ser integrada discursivamente na tradição da Política Externa Brasileira (PEB) em privilegiar instrumentos que permitam o desenvolvimento do País.

Diante desse panorama, esta pesquisa é orientada pelo questionamento: "Qual é o alcance da difusão do conceito de “Diplomacia da Inovação” na academia, a partir da primeira produção registrada em 2010?”. Para esta questão, a hipótese a ser testada considera que "a difusão do termo e conceito "Diplomacia da Inovação" na academia decorre da sua utilização em trabalhos de conclusão de curso, dissertações, teses e publicações em revistas científicas, cuja relação autoral dá-se com grupos de pesquisa e funcionários governamentais que abordam a temática de CT\&I, sendo a sua disseminação ainda incipiente em razão do reduzido número de trabalhos entre 2010 e 2019".

Metodologicamente realizou-se uma revisão de literatura via artigos, livros e sítios na internet para a primeira e a segunda seção do artigo. Assim, almejou-se contextualizar o tema, apresentando a conceituação e o histórico da DC e da DI.

Empreendeu-se a análise bibliométrica como base para a terceira seção, com o objetivo de buscar produções científicas que utilizassem o termo “Diplomacia da Inovação”. Dessa maneira, procurou-se mapear o alcance do conceito, entendimento e interpretação brasileira da DC, aqui representado por DI, via o mapeamento e sistematização da expressão em periódicos vinculados à base de dados do Google Scholar. Portanto, a análise bibliométrica executada tem como finalidade compreender a dimensão em que a DI é internalizada na produção acadêmica e científica. Como resultado, possibilitar-se-á a compreensão dessa linha de estudos da cooperação internacional e a identificação das abordagens utilizadas para tratar da DI.

O texto divide-se em três seções, além da introdução e conclusão. A primeira versará sobre a origem do termo "Diplomacia Científica", sua definição e utilização como instrumento de política externa. Na seção seguinte, será introduzida a perspectiva brasileira de DC, iniciando com a apresentação do conceito de "Diplomacia da Inovação", como proposta e modo de inserção do País no contexto internacional das relações em CT\&I, o que possibilitará sintetizar o seu histórico. Por fim, a terceira seção estará concentrada na identificação e análise qualitativa e quantitativa dos artigos que tratam sobre a DI.

\section{Diplomacia Científica}

Para uma série de questões contemporâneas, desde as agendas para o desenvolvimento sustentável, as negociações climáticas, as ameaças à segurança global ou à segurança alimentar; a Ciência, Tecnologia e 
Inovação (CT\&I), sobretudo a cooperação científica, tem se revelado como meio responsivo na política mundial. No entanto, a temática da CT\&I ainda é, em certa medida, marginal nos estudos das Relações Internacionais e, ao mesmo tempo, está entre as modalidades convencionais quando se trata de cooperação internacional (SKOLNIKOFF, 1993; WEISS, 2005). Devido à relevância e ao caráter pervasivo da CT\&I, ela apresenta capacidade de influenciar as relações internacionais e ser influenciada por estas relações (WEISS, 2005). Ademais, alguns autores, como Weiss (2005, p. 295), entendem que a CT\&I deveria ser um subcampo na teoria de Relações Internacionais.

As relações diplomáticas envolvendo a CT\&I não têm um termo consensual e unificador que as define e seja amplamente utilizado pelos atores, estatais ou não, que participam e promovem relações internacionais e cooperação na área (ACUTO; KALTOFEN, 2018a). Conforme aponta Aranda (2017, p. 8), a designação mais usual para o fenômeno é a de "Diplomacia Científica" (VARELA et al., 2017 apud ARANDA, 2017, p. 8) ou de "Diplomacia de Ciência” (ARROZ; MENDONÇA, 2016). Aranda (2017, p. 8) identificou também outras expressões utilizadas, como "Diplomacia da Inovação (JÚNIOR, 2010)”, “Diplomacia Científica e Tecnológica (MENDONÇA, 2015; Japan Cabinet Office, 2008)” ou “Diplomacia Científica, Tecnológica e de Inovação (Gobierno de España, 2016)". Outrossim, observa-se que, apesar da crescente importância da DC, principalmente por ser estudada e desenvolvida em relevantes centros de pesquisa ${ }^{5}$, haveria pouco interesse por parte de estudiosos das teorias dominantes de RI, pelo que se depreende da embrionária produção científica referente ao assunto (ACUTO; KALTOFEN, 2018a, 2018b; TUREKIAN, 2018) ${ }^{6}$.

A DC como conceito e prática não é um fenômeno novo. Historicamente, há autores que apontam Benjamin Franklin como o primeiro diplomata cientista estadunidense (WANG, 2013). Este pioneirismo em aplicar ciência e tecnologia à política externa (LORD, 2007; HUDDLE, 1980 apud FÄHNRICH, 2017, p. 688689) pode ser exemplificado com o Programa de Cooperação Científica entre Estados Unidos (EUA) e Japão em 1961.

Ressalta-se que o termo "Diplomacia Científica” foi criado por Nina V. Fedoroff, durante e para sua atuação no cargo de Assessora de Ciência e Tecnologia da Secretária de Estado dos EUA - Condoleezza Rice , no período de 2007 a 2010. A DC foi caracterizada como "novas atividades de política externa servindo tanto a humanidade quanto a construção de parcerias internacionais construtivas.” (ACUTO; KALTOFEN, 2018a, p. 9, tradução nossa) $)^{7}$. Originariamente, a DC já estava inserida no discurso estadunidense como uma ferramenta de soft power ${ }^{8}$ para a manutenção do poder e segurança dos EUA (FEDOROFF, 2008).

\footnotetext{
${ }^{5}$ Como no estadunidense Center for Science Diplomacy (CDS), que edita a revista “Science \& Diplomacy”; no britânico Royal Society, que aborda a questão da CT\&I; ou no indiano Research and Information System for Developing Countries (RIS, 2019), que foca a perspectiva sul-sul.

${ }^{6}$ É necessário informar que o propósito deste artigo não é trabalhar este debate teórico. Para um aprofundamento e melhor compreensão desta discussão, recomenda-se a leitura de artigos de Acuto e Kaltofen (2018a; 2018b). Para uma análise da DC pelo prisma do realismo, liberalismo e construtivismo, indicamos Aranda (2017).

7 “(...) Science diplomacy was introduced as referring to new foreign policy activities that serve 'humanity' as well as 'build constructive international partnerships" (FEDOROFF, 2009 apud ACUTO; KALTOFEN, 2018a, p. 9).

${ }^{8} \mathrm{O}$ conceito de soft power é apresentado, junto ao hard power, por Joseph S. Nye (2012) como uma das faces do poder. O soft power está alicerçado na capacidade do ator em utilizar a atração e cooptação, a partir dos seus recursos intangíveis (instituições, ideias, valores e cultura), e convertê-los em poder de facto para que atinja os resultados desejados. Nas palavras de Nye (2012, p. 44), o soft power “[...] é a capacidade de afetar outros utilizando meios cooptativos de ajuste de agenda, persuasão e produção de atração positiva para a obtenção de resultados preferidos”. Já o hard power pode ser entendido como um poder de comando, i.e., a capacidade que os Estados
} 
Neste sentido, Leite e Gayard (2019) corroboram tal entendimento, ao salientar a forma como outro Assessor de Ciência e Tecnologia do Secretário de Estado dos EUA do governo Barack Obama, Vaughan Turekian, interpreta a relação dos estados com a ciência, tratando a DC como instrumento de política externa. Ou seja, “Nações olham para a ciência para conquistar um dos três 'E’s da DC: expressar (express) o poder ou influência nacional; equipar (equip) tomadores de decisão com informação para apoiar as políticas e melhorar (enhance) relações bilaterais e multilaterais" (TUREKIAN, 2012, p. 1 apud LEITE; GAYARD, 2019, p. 3).

Outra definição que, além de reforçar a centralidade do Estado na prática da DC, também a destaca como um importante instrumento promotor de soft power, é a aportada por Davis e Patman (2015). Para eles, a DC é “o processo pelo qual os Estados se fazem representar e pelo qual defendem seus interesses no cenário internacional nas áreas relacionadas à aquisição, utilização e comunicação do conhecimento adquirido pelo método científico" (DAVIS; PATMAN, 2015, p. 4-5, tradução nossa) ${ }^{9}$.

Como mencionado anteriormente, há importantes associações anglo-americanas no centro do pensamento das Relações Internacionais estudando a temática: a estadunidense American Association for the Advancement of Science (AAAS), que criou Center for Science Diplomacy (CDS) em 2008, e a britânica Royal Society. Estes institutos prepararam conjuntamente o relatório intitulado "New Frontiers in Science Diplomacy: navigating the changing balance of power" não apenas considerado o texto referência, mas cujo conceito de DC se tornou o mais disseminado. Assim, a DC é apresentada como "[...] um conceito fluido, mas que pode ser utilmente aplicado ao papel da ciência, tecnologia e inovação em três dimensões de políticas [...] (ROYAL SOCIETY, 2010, p. v-vi); dimensões estas que foram esquematizadas e definidas no quadro abaixo:

Quadro 1 - Dimensões da Diplomacia Científica

\begin{tabular}{|c|c|}
\hline Dimensão & Definição \\
\hline Ciência na diplomacia & Informar objetivos de política externa com aconselhamento científico \\
\hline Diplomacia para a ciência & Facilitar a cooperação científica internacional \\
\hline Ciência para a diplomacia & $\begin{array}{c}\text { Utilizar a cooperação científica para melhorar relações internacionais } \\
\text { entre países e a solucionar problemas compartilhados }\end{array}$ \\
\hline
\end{tabular}

Fonte: elaborado pelas autoras a partir de informações de Royal Society (2010)

Outrossim, Acuto e Kaltofen (2018a, p. 11) concebem DC como “uma prática que tem por objetivo manter, cultivar, aprofundar e prolongar relações” (ACUTO; KALTOFEN, 2018a, p. 11, tradução nossa) ${ }^{10}$. Por isso, quando abordam a temática o fazem incluindo as profissões, os profissionais e as instituições relacionadas (ACUTO; KALTOFEN, 2018a, p. 12), com a finalidade de compreender a complexidade das relações ali estabelecidas. Ou seja, ao considerarem mais detidamente os estudos de ciência e de diplomacia no processo de DC, elas se referem a experiência de profissionais de política externa e de membros da

têm para conseguir os resultados que ensejam ao utilizar os seus recursos militares e econômicos, mediante a coerção e o pagamento (NYE, 2012).

9 "Science diplomacy is the process by which states represent themselves and their interests in the international arena when it comes to areas of knowledge - their acquisition, utilization and communication - acquired by the scientific method. It is a crucial, if under-utilized, specialty within the diplomatic constellation that can be used to address global issues, enhance co-operation between countries and leverage one country's influence over another. In this regard, science diplomacy is a significant generator of soft power - that potent form of attraction that harnesses national image, reputation, and brand." (DAVIS; PATMAN, 2015, p. 4-5)

10 "Science diplomacy is a practice that aims to maintain, cultivate, deepen and prolong relations." (ACUTO; KALTOFEN, 2018a, p. 11). 
comunidade científica - "os diplomatas científicos e os cientistas diplomáticos” respectivamente - e buscam entender como eles realmente trabalham em uma área cujas fronteiras são fluidas.

Por fim, apresentam-se duas perspectivas semelhantes que entendem a DC como meio para solucionar desafios compartilhados entre as nações, como questões climáticas ou pandêmicas. O Conselho de Academias da Finlândia, cuja finalidade é ser interface para o diálogo entre pesquisadores e tomadores de decisão políticas, concebe a DC com o foco na resolução conjunta de problemas globais comuns, que atingem vários Estados e regiões simultaneamente, demandando "soluções multidisciplinares encontradas na interface ciência-política” (THE COUNCIL OF FINNISH ACADEMIES, 2019).

Na mesma direção, acrescenta-se a acepção da The World Academy of Sciences (TWAS) para o avanço da ciência nos países em desenvolvimento, sediada em Trieste, na Itália. Nela o propósito é estudar DC para estimular o desenvolvimento da ciência nos países em desenvolvimento, pesquisando a temática e oferecendo cursos e capacitação. A TWAS, assim como as organizações apresentadas anteriormente, define a DC como um meio através do qual as nações resolvem questões climáticas ou pandêmicas, em que os cientistas apoiam tecnicamente os diplomatas, auxiliando na construção de laços de confiança e de acordos internacionais (TWAS, 2019).

Embora não haja um consenso sobre o conceito de DC, considera-se que a definição e os elementos apontados pelo Relatório da Royal Society (2010) formulado em conjunto com a AAAS servem como ponto inicial para a introdução na temática. Mesmo as Academias ou institutos de pesquisa fora do eixo angloestadunidense, como o Research and Information System for Developing Countries (RIS), consideram-na ponto de partida, acrescentando a questão do desenvolvimento tecnológico de seus países como um fim a ser buscado, assim como a importância de uma leitura do fenômeno pelas lentes do sul global.

\section{Diplomacia da Inovação}

Para entender a perspectiva brasileira de Diplomacia Científica (DC) e o porquê de o País adotar o termo Diplomacia da Inovação (DI), faz-se necessário apontar o êxito da assimilação da Cooperação Técnica Internacional (CTI) ${ }^{11}$ pelo Brasil, ao ter sido receptor de cooperação em ciência e tecnologia nas décadas de 1950/1980, como no caso do Programa PROCEDER. ${ }^{12}$ Até a década de 1960, a CTI apresentou perfil vertical, pois configurava um mecanismo de cooperação Norte-Sul, em que o doador era um país industrializado e o receptor, um país subdesenvolvido. Na década de 1970, há uma inflexão na proposta para a CTI, esta passa a ser operacionalizada como cooperação horizontal (UNDP, 1978), ou seja, Sul-Sul. Assim, a CTI, inserida na Cooperação Técnica entre Países em Desenvolvimento - CTPD (ANUNCIATO, 2013, p. 8), se transformaria em um instrumento de política externa de vários países “atrasados”, com a criação de agências de cooperação governamentais. No caso brasileiro, estabeleceu-se um Sistema Nacional de Cooperação Técnica (1969) e, no

\footnotetext{
${ }^{11}$ Esta cooperação busca auxiliar um país a promover mudanças estruturais nos seus sistemas produtivos por meio da transferência de conhecimento, experiência de sucesso e equipamentos, colaborando para capacitar os recursos humanos e fortalecer as instituições do país receptor.

${ }^{12}$ O Programa de Cooperação Nipo-Brasileiro para o Desenvolvimento Agrícola dos Cerrados (PROCEDER), realizado entre 1978 e 2001, visava o desenvolvimento de técnicas de produção e de agricultura sustentável no cerrado brasileiro para a promoção da produção de soja.
} 
Ministério das Relações Exteriores, a Agência Brasileira de Cooperação - ABC (1987), órgão central de formulação política (CERVO, 1994).

A CTPD sofreria um revés na década de 1990, com a redução da cooperação técnica horizontal via ABC. Contudo, nos anos 2000, houve uma reorientação que buscou novas formas autônomas de inserção internacional com parceiros diversificados e estratégicos para utilizar a PEB como um meio para o desenvolvimento interno (VIGEVANI; CEPALUNI, 2007). Nesse contexto, é observado que o Brasil altera seu papel na CTI e passa de país receptor para país doador (COSTA VAZ, 2007; PUENTE, 2010; IPEA, 2010 apud ANUNCIATO, 2014), possibilitando atuar ativamente na cooperação técnica Sul-Sul ${ }^{13}$ para o desenvolvimento a fim de estimular a inovação e a mudança tecnológica (ANUNCIATO, 2014).

Apesar da criação e institucionalização destes mecanismos que possibilitaram a exitosa cooperação no nível internacional, a $\mathrm{ABC}$ ainda não estaria estruturada para conceber e operacionalizar a DC como instrumento de PEB. Ao delinear, como antecedente necessário para o Brasil o “desenvolvimento econômicosocial e a criação de uma economia do conhecimento” (CRUZ JUNIOR, 2010, p. 308), pressupõe realizá-lo somente por meio da DI, ou seja, preconizando-se o desenvolvimento sustentável. Respaldaria esta perspectiva, o reconhecimento de que a diplomacia da ciência trataria, especificamente, de "instrumento de geração de confiança e mitigação de conflitos” utilizado pelos países industrializados (CRUZ JUNIOR, 2010, p. 308).

Nesse sentido, a escolha da nomenclatura também estaria associada à distinção entre a CTI e a DI. Na primeira, haveria a transferência de conhecimentos consolidados, sobretudo, na cooperação realizada por atores governamentais, como a Embrapa e o SENAI, por exemplo. Na DI, diferentemente, o Brasil pretenderia promover o desenvolvimento socioeconômico via a construção de capacitação tecnológica, conforme abordado pelo diplomata Ademar Seabra da Cruz Junior e no Programa de Diplomacia da Inovação (PDI) do MRE (BRASIL, 2019). Logo, a diplomacia brasileira utiliza-se do termo "Diplomacia da Inovação" para diferenciar da DC, pois sua elaboração conceitual procura realçar a dicotomia entre países já habilitados tecnologicamente e países cuja lacuna tecnológica seria um obstáculo à prática da DC, como no caso do Brasil.

Ademar Seabra da Cruz Junior é um dos grandes expoentes do Ministério das Relações Exteriores do Brasil no que tange ao assunto de CTI e, particularmente, da questão da Diplomacia da Inovação. Ele interpreta que os países emergentes não teriam níveis educacionais, de produtividade e de diversificação produtiva que lhes possibilitasse superar as desigualdades. Em razão disso, o cabedal diplomático desses países deveria ser direcionado a "aquisição de um novo perfil produtivo-tecnológico, que lhes permita redefinir, por sua vez, sua posição e inserção na divisão internacional do trabalho” (CRUZ JUNIOR, 2010, p. 300-301). Assim, a PEB deveria buscar trabalhar para

[...] definir uma orientação clara e firme para uma diplomacia da ciência e da inovação, que permita ao Brasil gerar vantagens competitivas dinâmicas em detrimento das vantagens comparativas estáticas e tradicionais. A diplomacia da inovação passa a representar, nesse cenário, uma ferramenta auxiliar de primeira grandeza para a economia do desenvolvimento. (CRUZ JUNIOR, 2010, p. 300)

\footnotetext{
13 “A cooperação técnica sul-sul brasileira caracteriza-se pela transferência de conhecimentos, pela ênfase na capacitação de recursos humanos e pela concepção de projetos que reconheçam as especificidades de cada país.” (MRE, 2011 apud ANUNCIATO, 2014).
} 
No que concerne ao Programa de Diplomacia da Inovação (PDI), empreendido pelo Itamaraty, pretende expor internacionalmente o Brasil como produtor de conhecimento, produtos e serviços na temática de ciência e tecnologia. ${ }^{14}$ Por isso, objetiva promover o perfil do País a ecossistemas estrangeiros de inovação, para detectar parcerias e atrair investimentos, dar suporte a internacionalização de "startups", "auxiliar na mobilização da diáspora científica brasileira no exterior e fomentar a colaboração entre parques tecnológicos brasileiros e estrangeiros" (BRASIL, 2019). O fato de atuar com diferentes países, desenvolvidos e em desenvolvimento (CRUZ JUNIOR, 2010, p. 308), parece dirigir a DI à oportunidade para a cooperação em inovação com países em desenvolvimento como Índia e China, com maior potencial e influência nesta área.

Assim, o Brasil não formula um conceito de DC, mas ao adotar a terminologia de "Diplomacia da Inovação", opta por difundir a manutenção do discurso que ainda é, em algum grau, "desenvolvimentista”. A cooperação, consequentemente, tem sempre a finalidade de impulsionar o desenvolvimento tecnológico que gerará crescimento econômico e melhora social.

\section{O panorama da pesquisa científica brasileira sobre a Diplomacia da Inovação}

Esta seção tem como objetivo realizar o mapeamento e sistematização qualitativa e quantitativa sobre a Diplomacia da Inovação (DI) em artigos e demais produções científicas indexadas na base de dados do Google Scholar $^{15}$. A busca foi realizada nos meses de setembro e novembro de 2019, e em janeiro de 2020, contemplando artigos entre os anos de 2010 e 2019.

Tendo em vista que a finalidade desta pesquisa é subsidiar a definição conceitual de "Diplomacia da Inovação", os descritores ${ }^{16}$ selecionados foram: “Diplomacia da Inovação" e "Brasil”. Com relação à estratégia de busca ${ }^{17}$ na ferramenta de pesquisa Google Scholar, utilizou-se “"Diplomacia da Inovação” AND "Brasil”", procurando abranger todos os tipos de documentos (artigos, papers, palestras, livros, relatórios, monografias, teses e dissertações). Tal estratégia obteve o retorno de um portfólio de $20^{18}$ documentos indexados na plataforma para os três períodos em que a busca foi executada.

No entanto, com a verificação dos documentos, observou-se a duplicação de dois itens. Dessa maneira, o resultado final da busca nos três períodos formou um portfólio com 18 produções. Foi realizada também a pesquisa com a estratégia de busca apenas com o descritor “Diplomacia da Inovação”. Obteve-se a mesma quantidade de documentos indexados nas pesquisas anteriores, isto é, 18 produções científicas acrescida da duplicação de dois itens.

\footnotetext{
${ }^{14}$ Para informações sobre eventos apoiados pelo PDI entre os anos de 2017 e 2018, ver Brasil (2019).

${ }^{15}$ As bases utilizadas para a pesquisa foram: Google Scholar, Web of Science, Redalyc, Scopus, Scielo e a Biblioteca Digital Brasileira de Teses e Dissertações (BDTD). No entanto, somente o Google Scholar coletou dados que abarcassem os dois grupos de descritores, conforme a estratégia de pesquisa realizada em setembro de 2019, atualizada em novembro de 2019 e replicada em janeiro de 2020 . As demais bases não apresentaram resultados, por isso, o portfólio foi constituído apenas com os resultados do Google Scholar.

${ }^{16}$ De acordo com Nobre e Bernardo (apud POMPEI, 2010, p. 231), descritores são "um termo ou palavra-chave que a base de dados utiliza para indexar o artigo". A utilização de descritores para pesquisas em bases de dados confere maior acurácia à busca realizada (POMPEI, 2010).

${ }^{17}$ Nas palavras de Farenhof e Fernandes (2016, p. 7), estratégia de busca é "um conjunto de procedimentos que definem os mecanismos da pesquisa e a recuperação de informações online".

${ }^{18}$ Cabe informar que houve a repetição de dois textos na pesquisa na base do Google Scholar, devido ao registro incompleto do título ou do nome do autor do trabalho, nos casos da monografia de Aline Regina Fernandes e do livro de Paulo Roberto de Almeida.
} 
A metodologia adotada para a identificação, seleção e sistematização dos artigos foi dividida em três etapas. A primeira etapa consistiu na utilização da ferramenta Google Scholar para pesquisar trabalhos que apresentassem os descritores "Diplomacia da Inovação" e "Brasil”.

Na segunda etapa, com a análise dos textos identificados na primeira, foi possível selecionar artigos e produções científicas em dois grupos: i) produções que apenas mencionam a "Diplomacia da Inovação", sem aprofundamento na utilização ou discussão do conceito; e ii) produções que utilizam o termo "Diplomacia da Inovação" como abordagem central em seu texto; ou que estabeleçam uma discussão entre este conceito e a DC, ou entre este conceito e a cooperação internacional em CT\&I. Mediante esse processo, a estratégia de busca na base do Google Scholar permitiu a seleção de 11 dos 18 artigos e demais produções científicas, como monografias, teses, dissertações e relatórios, os quais são categorizados como pertencentes ao segundo grupo.

Por fim, a terceira etapa consistiu na elaboração de um banco de dados dos artigos e demais produções científicas selecionadas e categorizados dentro do segundo grupo. Dessa maneira, através das três etapas metodológicas, foi possível sistematizar os artigos do segundo grupo com base em: identificação por autor, temáticas principais, periódico ou instituição em que foi realizada a publicação, recorte institucional e temporal.

Para facilitar as exposições e análises seguintes, o Quadro 2 elenca por ordem alfabética os nomes dos autores e o título de suas respectivas produções, identificando origem e ano da publicação. Baseado nesses dados é possível analisar tanto as citações dos artigos e seus autores no Google Scholar (Gráfico 3), assim como o cruzamento entre os artigos, isto é, os autores mencionados no Quadro 3 que citam outros autores presentes no mesmo quadro. 
Quadro 2 - Autores e suas produções ${ }^{19}$

\begin{tabular}{|c|c|c|c|}
\hline Nomes dos Autores & Título & $\begin{array}{l}\text { Origem da } \\
\text { Publicação }\end{array}$ & Ano \\
\hline $\begin{array}{l}\text { 1. ARANDA, Jorge Eduardo } \\
\text { Ferreira Silva }\end{array}$ & $\begin{array}{l}\text { Diplomacia científica: das boas práticas } \\
\text { internacionais a um modelo nacional ótimo }\end{array}$ & $\begin{array}{l}\text { Universidade } \\
\text { Técnica de Lisboa } \\
\text { (ULisboa) }\end{array}$ & 2017 \\
\hline $\begin{array}{l}\text { 2. BALSADI, Otavio } \\
\text { Valentim; NASCIMENTO, } \\
\text { Petula Ponciano }\end{array}$ & Governança global ${ }^{20}$ & Embrapa & 2018 \\
\hline 3. CRESTANA, Silvio & $\begin{array}{l}\text { Relatório do seminário preparatório "Inserção da } \\
\text { CT\&I nos fóruns internacionais" }\end{array}$ & $\begin{array}{l}\text { Parecerias } \\
\text { Estratégicas - } \\
\text { CGEE }\end{array}$ & $2010 \mathrm{a}$ \\
\hline 4. CRESTANA, Silvio & $\begin{array}{c}\text { Relatório da sessão “O Brasil na nova geografia } \\
\text { global” }\end{array}$ & $\begin{array}{l}\text { Parecerias } \\
\text { Estratégicas - } \\
\text { CGEE }\end{array}$ & $2010 \mathrm{~b}$ \\
\hline $\begin{array}{l}\text { 5. CRUZ JUNIOR, Ademar } \\
\text { Seabra da }\end{array}$ & Relatório da sessão "Diplomacia da inovação" & $\begin{array}{l}\text { Parecerias } \\
\text { Estratégicas - } \\
\text { CGEE }\end{array}$ & 2010 \\
\hline $\begin{array}{l}\text { 6. CRUZ JUNIOR, Ademar } \\
\text { Seabra da }\end{array}$ & $\begin{array}{l}\text { Globalização, inovação e sistema internacional: o } \\
\text { Brasil e as transformações da economia mundial }\end{array}$ & $\begin{array}{l}\text { Revista FAAC } \\
\text { (UNESP) }\end{array}$ & $2011 \mathrm{a}$ \\
\hline $\begin{array}{l}\text { 7. CRUZ JUNIOR, Ademar } \\
\text { Seabra da }\end{array}$ & $\begin{array}{c}\text { Diplomacia, desenvolvimento e sistemas nacionais } \\
\text { de inovação: estudo comparado entre Brasil, China } \\
\text { e Reino Unido }\end{array}$ & $\begin{array}{c}\text { Instituto Rio } \\
\text { Branco (IRBR)/ } \\
\text { Fundação } \\
\text { Alexandre de } \\
\text { Gusmão (FUNAG) }\end{array}$ & $2011 b$ \\
\hline $\begin{array}{l}\text { 8. FERNANDES, Aline } \\
\text { Regina }\end{array}$ & $\begin{array}{l}\text { A cooperação científica e tecnológica no âmbito da } \\
\text { Cooperação Sul-Sul: um olhar na perspectiva da } \\
\text { inserção internacional brasileira }\end{array}$ & $\begin{array}{l}\text { Universidade de } \\
\text { Brasília (UNB) }\end{array}$ & 2011 \\
\hline $\begin{array}{l}\text { 9. NASCIMENTO, Petula } \\
\text { Ponciano }\end{array}$ & $\begin{array}{l}\text { A trajetória da cooperação científica internacional } \\
\text { da Embrapa: do emparelhamento tecnológico } \\
\text { (catching-up) com a revolução verde à liderança } \\
\text { tecnológica na agricultura tropical. }\end{array}$ & $\begin{array}{l}\text { Universidade } \\
\text { Federal do Rio de } \\
\text { Janeiro (UFRJ) }\end{array}$ & 2016 \\
\hline $\begin{array}{l}\text { 10. PEDROSO, Gabriela } \\
\text { Bassoli }\end{array}$ & $\begin{array}{l}\text { O Lugar do Brasil na Diplomacia Científica da } \\
\text { Suécia }\end{array}$ & $\begin{array}{l}\text { Universidade } \\
\text { Federal de Santa } \\
\text { Catarina (UFSC) }\end{array}$ & 2019 \\
\hline 11. KOCH, Julia Cristina & $\begin{array}{c}\text { O Papel do Brasil na Diplomacia Científica } \\
\text { Dinamarquesa }\end{array}$ & $\begin{array}{c}\text { Universidade } \\
\text { Federal de Santa } \\
\text { Catarina (UFSC) }\end{array}$ & 2019 \\
\hline
\end{tabular}

Fonte: elaborado pelas autoras. ${ }^{21}$

\footnotetext{
${ }^{19}$ Foram retificados os anos de publicação dos artigos da Revista Parcerias Estratégicas (itens 3, 4 e 5 do quadro). Na base de pesquisa Google Scholar esses artigos foram identificados como publicados em 2012, o que só foi possível corrigir com acesso ao arquivo e ao seu conteúdo, constatando-se tratar de edição de 2010, conforme também consta no Quadro 2.

${ }^{20}$ Capítulo 6. (DINIZ et al., 2018).

${ }^{21}$ Autores e títulos dos trabalhos corretamente grafados, já excluídos os itens repetidos.
} 
Gráfico 1- Distribuição dos trabalhos relacionados à Diplomacia da Inovação no Google Scholar (2010-2019): ano e quantidade de publicações, instituição, autor/cargo.

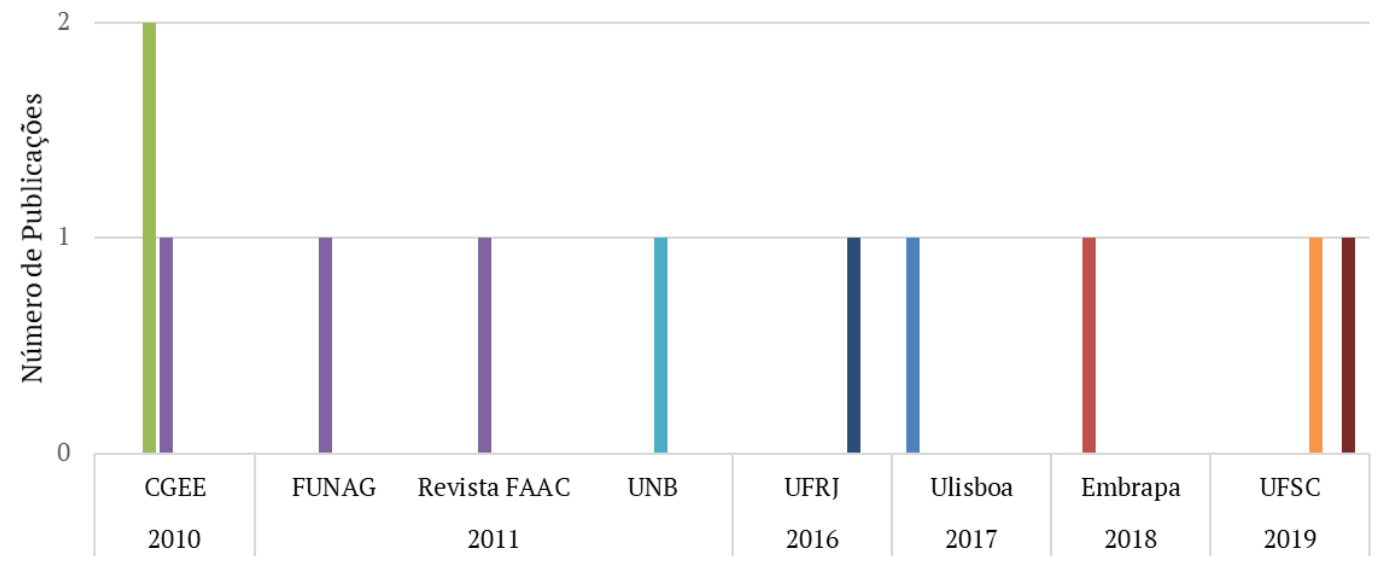

Autor/Cargo

- ARANDA, J. F. S. - Diplomata português

- CRESTANA, S. - Ex-diretor-Presidente da Embrapa

- FERNANDES, A. R. - Funcionária do MCTIC

BALSADI, O.; NASCIMENTO, P.P. - Pesquisadores Embrapa

n CRUZ JUNIOR, A. S. da - Diplomata brasileiro

- NASCIMENTO, P.P. - Pesquisadora da Embrapa Solos

๓ KOCH, J. C. - Bacharel em RI pela UFSC

- PEDROSO, G. B. - Analista de RI (Bacharel UFSC)

Fonte: elaborado pelas autoras.

O primeiro aspecto da análise concerne à data de publicação dos trabalhos. Conforme o Gráfico 1, as primeiras menções do conceito em artigos indexados pela base de dados utilizada ocorrem em 2010 com três artigos no periódico “Parcerias Estratégicas”, publicação do Centro de Gestão e Estudos Estratégicos (CGEE). Tais artigos são de autoria de dois funcionários de entidades públicas do governo federal. O primeiro, Ademar Seabra da Cruz Junior, é diplomata do Ministério das Relações Exteriores (MRE) e atual cônsul-geral adjunto do Brasil no Canadá, com um artigo. O segundo é Silvio Crestana, ex-Diretor-Presidente da Empresa Brasileira de Pesquisa Agropecuária (Embrapa) que atuou na internacionalização das atividades da empresa, por sua vez, com dois artigos. Tais informações evidenciam a origem e proeminência do termo "Diplomacia da Inovação" nos meios diplomáticos e governamentais.

No ano seguinte, cabe mencionar o livro de Ademar Seabra da Cruz Junior, intitulado "Diplomacia, desenvolvimento e sistemas nacionais de inovação: estudo comparado entre Brasil, China e Reino Unido”. A obra indexada é resultado da dissertação do autor, apresentada no Curso de Altos Estudos (CAE) do MRE, em novembro de 2009. O diplomata também é autor do segundo artigo (Revista FAAC/UNESP) que compõe as publicações sobre o tema em 2011. O terceiro documento é o trabalho de conclusão de especialização em Relações Internacionais de Aline Regina Fernandes, funcionária do Ministério da Ciência, Tecnologia Inovações e Comunicação (MCTIC). Nesse sentido, é possível observar, novamente, a origem e utilização do termo nas funções diplomáticas e governamentais, como fruto da formação e experiência desses profissionais.

Retornando à distribuição temporal das publicações, constata-se o intervalo de cinco anos, entre 2011 e 2016, em que não há publicações que tratem sobre o tema "Diplomacia da Inovação", segundo o indexador utilizado. Infere-se que tal lacuna de publicações com o tratamento do vocábulo é consequência do insulamento do termo em meios diplomáticos e governamentais. Isso sugere um afastamento entre o que é 
produzido em instâncias governamentais, por funcionários do governo federal e do corpo diplomático, em relação às universidades brasileiras, o que acarretou uma morosidade para que a "Diplomacia da Inovação" fosse incorporada em produções acadêmicas.

Nas publicações dos anos seguintes foi possível verificar a difusão da utilização do termo em trabalhos produzidos nas universidades brasileiras e portuguesas. Além disso, para corroborar nesta difusão identificase, mais uma vez, a conexão entre funcionários governamentais e a academia, como explicitado no caso da publicação portuguesa. Embora produzida em um ambiente acadêmico, fruto de uma Dissertação de Mestrado em Relações Internacionais, defendida na Universidade de Lisboa, trata-se do diplomata português Jorge Eduardo Ferreira da Silva Aranda ${ }^{22}$ trabalhando a seara da DC como possível instrumento de política externa de seu país. Ou seja, ao analisar a inserção de Portugal, o diplomata identifica o vocábulo "Diplomacia da Inovação" como sendo a denominação escolhida pela diplomacia brasileira para referir-se a DC.

Outros pesquisadores relacionados ao Estado brasileiro pertencem aos quadros da Embrapa, e exploram temas relativos à perspectiva da empresa alusivos à capacitação tecnológica, cooperação internacional e inovações agrícolas, conforme o Quadro 4. A Pesquisadora da Embrapa Solos, Petula Ponciano Nascimento, tem duas publicações: sua tese de doutorado no Instituto de Economia, na Universidade Federal do Rio de Janeiro (2016), e outra especificamente para a Embrapa (2018), em coautoria com Otavio Valentim Basaldi, Pesquisador da Secretaria de Inteligência e Relações Estratégicas da Embrapa. Assim, percebe-se neste enquadramento a tendência inversa: primeiro o conceito é aplicado na tese de doutorado, depois em um capítulo do ebook versando sobre a colaboração da empresa como instituição para a governança global.

Cabe ressaltar que as duas publicações do ano de 2019 integram monografias da graduação de Relações Internacionais da Universidade Federal de Santa Catarina (UFSC) ${ }^{23}$. A produção dessas monografias está atrelada às atividades do grupo de pesquisa do CNPq "Relações Internacionais e Ciência, Tecnologia e Inovação - RICTI”, vinculado à UFSC. O grupo RICTI, criado em 2016, apresenta como uma das suas linhas de pesquisa a Diplomacia científica, tecnológica e da inovação, a qual tem como coordenador o diplomata Ademar Seabra da Cruz Junior. Essa ação do grupo possibilita a difusão do conceito utilizado pelo corpo diplomático e governamental para tratar internacionalmente da política de cooperação em CT\&I. Ademais, demonstra o movimento de aproximação entre o que é produzido na academia e em esferas da administração pública.

Quando se analisa os periódicos ou instituições em que os documentos foram publicados, é possível observar de maneira mais acurada a concentração e difusão gradual de produções sobre a DI. Conforme demonstra o Gráfico 1, quatro dos oito periódicos ou instituições estão ligadas aos órgãos governamentais que atuam direta ou indiretamente na internacionalização da ciência. Quando comparados, os Gráficos 1 e 2 evidenciam a origem do vocábulo no meio diplomático brasileiro. As demais publicações que o constituem são monografias, dissertações e teses, as quais têm como instituição de origem universidades públicas brasileiras e uma portuguesa. Consoante com o já mencionado, recorda-se que a dissertação portuguesa foi

\footnotetext{
${ }^{22}$ Atual Diretor de Serviços da Direção de Serviços para os Assuntos de Segurança e Defesa (DSD) da República Portuguesa.

${ }^{23}$ Gabriela Bassoli Pedroso, Analista de Relações Internacionais (Bacharel em Relações Internacionais pela UFSC), e Julia Cristina Koch, Bacharel em Relações Internacionais pela UFSC.
} 
defendida por um diplomata da República Portuguesa, o que reforça a hipótese de correlação entre governo e academia na temática de CT\&I, diferenciando a nomenclatura de DC para Portugal e DI para o Brasil.

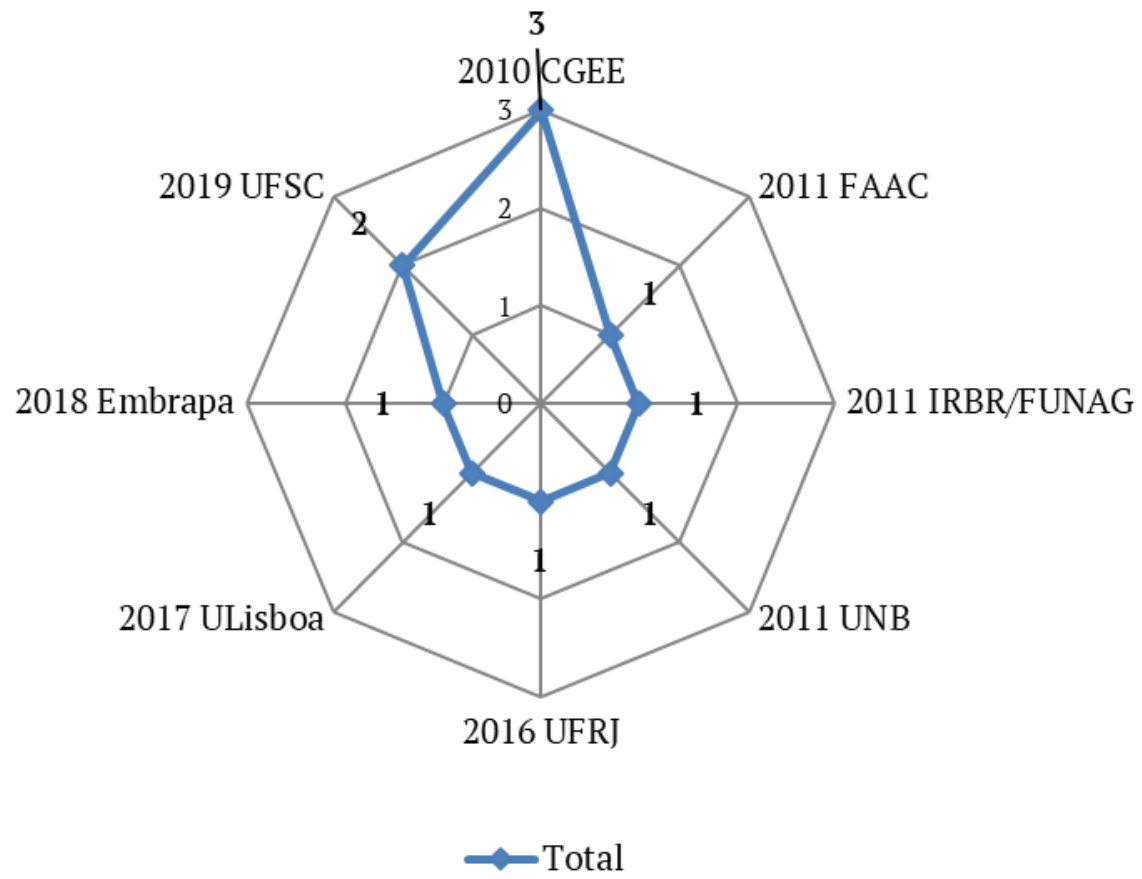

Fonte: elaborado pelas autoras.

Segundo o exposto no Gráfico 3, o livro de Cruz Junior (2011b) é o mais citado (sete vezes), autor cujo conceito de "Diplomacia da Inovação" é o mais referenciado, seguido de Fernandes (2011), com uma citação. No entanto, apesar de apenas estas duas produções constarem com contagem de citação na base de dados, foi verificado que há citações de outras publicações que estão presentes na seleção do Quadro 2, como as de Cruz Junior (2010) e Crestana (2010a; 2010b).

Os textos de Cruz Junior (2010) e Crestana (2010a; 2010b), apesar de apresentarem zero citações nos resultados da base de dados, são utilizados em duas publicações (ARANDA, 2017; FERNANDES, 2011; NASCIMENTO, 2016) presentes no Quadro $3^{26}$. Contudo, os autores (ARANDA, 2017; FERNANDES, 2011; NASCIMENTO, 2016) referenciaram as obras de Cruz Junior e Crestana como de autoria do Embaixador André Amado ou com grafias diferentes, conforme Quadro 3. Postula-se que isso se deve ao fato de o Embaixador Amado ser mencionado nos textos supracitados como apresentador de painel na " 4 a Conferência Nacional de Ciência Tecnologia e Inovação para um Desenvolvimento Sustentável ( $4^{\mathrm{a}}$ CNCTI)”, em 2010, que foi relatada

\footnotetext{
${ }^{24}$ Observar que o dado no gráfico “Universidade de Brasília (MCTIC)" refere-se ao trabalho de conclusão de especialização em Relações Internacionais de Aline Regina Fernandes, funcionária do MCTIC, na UnB e, portanto, foi contabilizado como uma publicação ligada aos órgãos e entidades governamentais.

${ }^{25}$ A busca na plataforma Google Scholar apresentou a tese de Nascimento (2016) disponível no banco de dados da Embrapa (repositório Alice). No entanto, verificou-se que ela é originária do Instituto de Economia, Universidade Federal do Rio de Janeiro, instituição que foi inserida no Gráfico 1. Neste caso, a Embrapa por afinidade temática indexa a tese em seus bancos de dados.

${ }^{26}$ Para a formulação do Gráfico 3 optou-se pela omissão destas citações ou referências. Foram priorizados os dados de citação fornecidos pelo Google Scholar e pelo software Publish or Perish.
} 
nos artigos. Isto posto, essa falha, junto às referenciações de autores como Cruz Junior colocadas de maneiras diferentes, constitui uma limitação dessa pesquisa. Visto que tal questão restringe o mapeamento por completo de publicações que citam Cruz Junior e Crestana e, até mesmo, os demais autores e produções aqui apresentados.

Gráfico 3 - Número de citações por autor

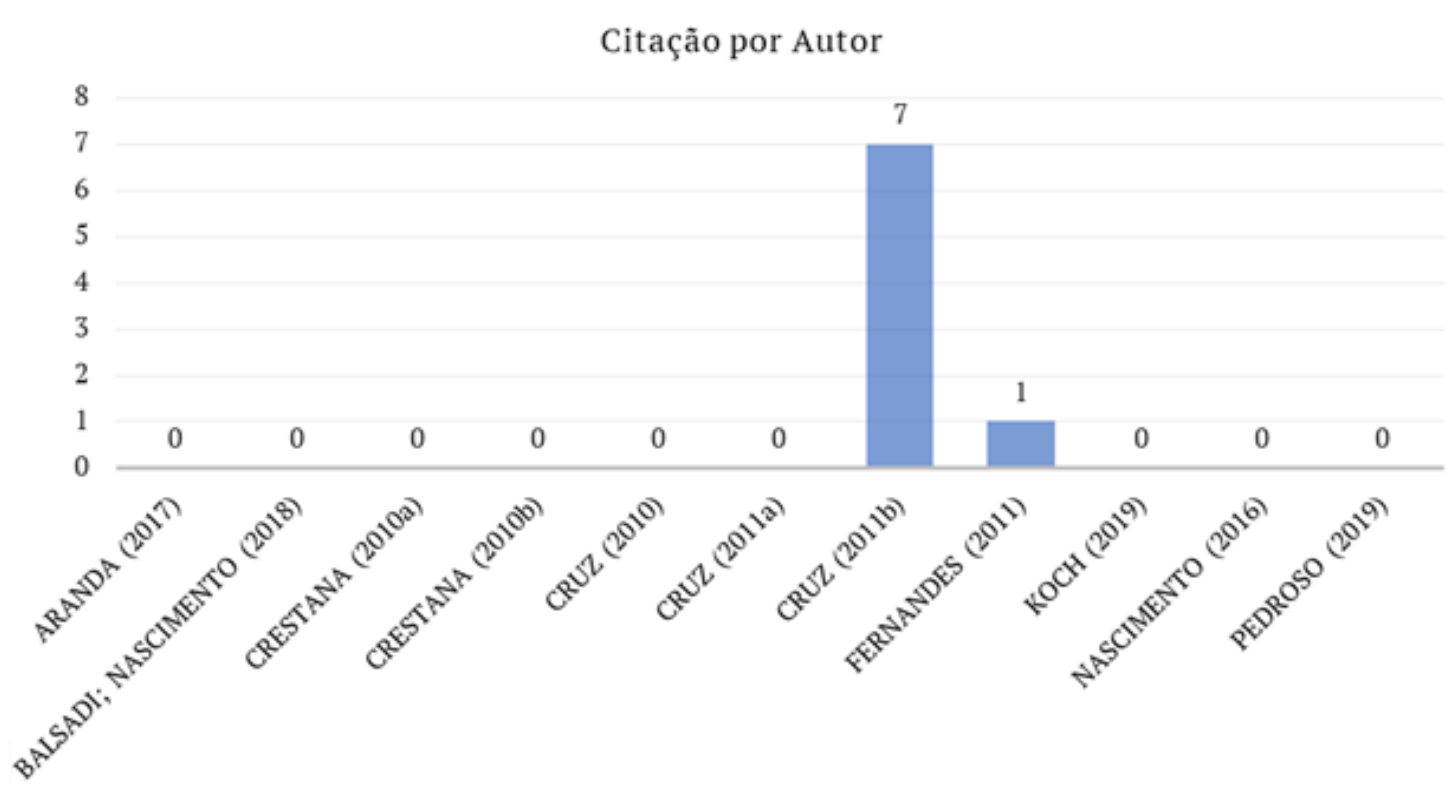

Fonte: elaborado pelas autoras.

No Quadro 3, foram sistematizados cinco dos onze artigos, monografias, teses e dissertações que citam e referenciam os autores chave quando se trata da "Diplomacia da Inovação", isto é, Cruz Junior e Crestana.

Quadro 3 - Referências cruzadas entre os onze documentos selecionados

\begin{tabular}{|c|c|}
\hline Autor & Cita e Referencia \\
\hline ARANDA, 2017 & CRESTANA, 2010a; CRUZ JUNIOR, 2010, mas cita Cruz Junior como “(JÚNIOR, \\
2010)”.
\end{tabular}

Fonte: elaborado pelas autoras.

Como último aspecto da análise, verificaremos a temática principal ${ }^{27}$ de cada um dos onze documentos selecionados. De acordo com o observado no Quadro 4, é possível afirmar que o vocábulo

\footnotetext{
${ }^{27}$ A verificação da temática principal dos artigos foi realizada a partir da leitura dos resumos, palavras-chaves (algumas sendo inseridas no Quadro 4), seções introdutórias e conclusivas dos artigos, em casos em que os artigos não possuíam resumos e palavras-chaves, foi realizada a leitura de suas seções introdutórias e conclusivas; para monografias, teses e dissertações foram realizadas as leituras dos resumos e palavras-chaves.
} 
"Diplomacia da Inovação” é utilizado para tratar das estratégias de inserção brasileira no cenário internacional de CT\&I, com predominância da inovação. Ainda, a inserção brasileira é abordada a partir da cooperação internacional, instrumentalizada mediante a DI.

Quadro 4 - Autores e temáticas principais abordadas em suas publicações

\begin{tabular}{|c|c|}
\hline Autores e ano & Temática Principal \\
\hline 1. ARANDA, 2017 & $\begin{array}{l}\text { Diplomacia científica; política externa; política de ciência e tecnologia; } \\
\text { internacionalização; Portugal. }\end{array}$ \\
\hline $\begin{array}{l}\text { 2. BALSADI; NASCIMENTO, } \\
2018\end{array}$ & $\begin{array}{l}\text { Governança global; instituições de CT\&I; Embrapa; Objetivos de } \\
\text { Desenvolvimento Sustentável; }\end{array}$ \\
\hline 3. CRESTANA, 2010a & $\begin{array}{l}\text { Fóruns internacionais; CT\&I; desenvolvimento sustentável; diplomacia da } \\
\text { inovação; Brasil; }\end{array}$ \\
\hline 4. CRESTANA, 2010b & Política brasileira para a CT\&I; inovação; internacionalização. \\
\hline 5. CRUZ JUNIOR, 2010 & Diplomacia da inovação; inovação; política brasileira de inovação. \\
\hline 6. CRUZ JUNIOR, 2011a & $\begin{array}{l}\text { Inovação; competitividade; globalização econômica; sistema econômico } \\
\text { internacional contemporâneo. }\end{array}$ \\
\hline 7. CRUZ JUNIOR, 2011b & Diplomacia; globalização; política de inovação; sistemas de inovação. \\
\hline 8. FERNANDES, 2011 & $\begin{array}{l}\text { Cooperação científica e tecnológica; cooperação técnica para o } \\
\text { desenvolvimento; cooperação Sul-Sul brasileira. }\end{array}$ \\
\hline 9. NASCIMENTO, 2016 & $\begin{array}{l}\text { Cooperação internacional; Embrapa; desenvolvimento científico e tecnológico; } \\
\text { inovações agrícolas. }\end{array}$ \\
\hline 10. $\mathrm{KOCH}, 2019$ & $\begin{array}{l}\text { Diplomacia científica; diplomacia da inovação; cooperação Brasil - Dinamarca; } \\
\text { acordos bilaterais em CT\&I. }\end{array}$ \\
\hline 11. PEDROSO, 2019 & $\begin{array}{l}\text { Diplomacia científica; diplomacia da inovação; CT\&I; Acordos Bilaterais; } \\
\text { relações Brasil-Suécia. }\end{array}$ \\
\hline
\end{tabular}

Fonte: elaborado pelas autoras.

Percebe-se que há autores que aplicam a perspectiva da DI para as relações de cooperação entre o Brasil e parceiros do sul global, sob a ótica da cooperação Sul-Sul e da cooperação técnica para o desenvolvimento (CTPD) (BALSADI; NASCIMENTO, 2018; CRESTANA, 2010a; CRESTANA, 2010b; CRUZ JUNIOR, 2010; CRUZ JUNIOR, 2011a; CRUZ JUNIOR, 2011b; FERNANDES, 2011; NASCIMENTO, 2016). Mas também há aqueles que aplicam para abordar as relações com parceiros do norte global, a partir de acordos bilaterais de cooperação em CT\&I (KOCH, 2019; PEDROSO, 2019). Neste último caso, apesar de a DI do Brasil não ser em si o foco dos trabalhos, mas sim a DC de países do norte em relação ao Brasil, as autoras discutem a perspectiva brasileira de DI para o tema e como ela dialoga com as ações de DC de outros países.

Desse modo, é possível inferir que a utilização do conceito de DI para a investigação de uma diplomacia brasileira para a CT\&I ainda é incipiente na academia. Ou seja, ainda que o conceito de DI, isto é, a perspectiva brasileira da DC, comece a se difundir aos poucos para a academia, ele permanece concentrado nas produções de funcionários governamentais. Estes são responsáveis pela construção do conceito, como no caso de Cruz Junior e Crestana, e sua implementação através de órgãos como a Embrapa. 


\section{Considerações finais}

A opção brasileira para a Diplomacia Científica (DC), sob a nomenclatura "Diplomacia da Inovação" (DI), remete a compreensão de que, por ser um País emergente, com carência educacional, baixa produtividade e diversificação produtiva, haveria um impeditivo para realizar uma DC. Visto que o Brasil precisaria atingir um perfil produtivo-tecnológico que o habilitasse a ser um competidor em CT\&I com os países desenvolvidos, sua política externa deveria privilegiar a aquisição deste conhecimento.

A utilização do termo e conceito da DI está alicerçada nos objetivos brasileiros para informar, no cenário internacional de cooperação em CT\&I, o seu entendimento do processo como interessado no desenvolvimento sustentável com a colaboração entre países em desenvolvimento. Dessa maneira, busca também diferenciá-lo do conceito dos países desenvolvidos, isto é, a DC. Nesse sentido, uma vez que o conceito de DI se consolide como discurso diplomático e possa vir a se tornar uma ferramenta de política externa, este conceito poderia ser instrumentalizado como um recurso de soft power. Nessa perspectiva, a instrumentalização do termo e conceito de DI para defender os interesses brasileiros no cenário internacional seria a partir de uma posição identitária de país em desenvolvimento, prezando pela cooperação em prol do desenvolvimento sustentável e desafios comuns no campo da CT\&I entre estes países.

A presente análise partiu do entendimento de que a perspectiva brasileira de DC foi fundamentada na concepção de DI, termo desenvolvido no corpo diplomático brasileiro. Com base nisso, foi possível analisar a difusão do conceito na produção acadêmica sobre cooperação internacional em CT\&I. A pesquisa corroborou a hipótese de que a utilização do conceito de DI na academia, desconsiderando órgãos governamentais como MRE e Embrapa, ainda é embrionária.

A partir de uma análise panorâmica da pesquisa científica brasileira sobre DI, observou-se movimentos de criação de um grupo de pesquisa e extensão, no curso de Relações Internacionais da UFSC. O RICTI desenvolve pesquisas utilizando-se do conceito proposto pelo corpo diplomático, e tem como um de seus coordenadores o atual cônsul-geral adjunto do Brasil no Canadá, Ademar Seabra da Cruz Junior, diretamente ligado com a pesquisa sobre DI. Os graduandos e graduandas integrantes do grupo de pesquisa estão produzindo trabalhos conectados com a DI, como pode-se observar no ressurgimento de publicações após um hiato entre 2016 e 2019, conforme o Quadro 2. O caso do grupo RICTI possui uma dupla característica: o insulamento, visto que tem a participação de Cruz Junior, mas também de inserção inicial do DI na academia.

É importante ressaltar outro ambiente de discussão e produção sobre a DI viabilizado pela Escola São Paulo de Ciência Avançada em Diplomacia Científica e Diplomacia da Inovação (InnSciDSP) ${ }^{28}$, organizado pelo Instituto de Relações Internacionais (IRI-USP). O espaço possibilitou, em 2019, debate e a apresentação de estudos teóricos e de caso sobre inovação e DI entre representantes do setor privado, governos, universidades e organizações internacionais e estudantes de pós-graduação de diferentes nacionalidades e áreas de conhecimento (FAPESP, 2019; INNSCIDSP, 2019a). Os participantes do evento criaram o documento

\footnotetext{
${ }^{28}$ Desconsiderou-se tal evento na realização da análise bibliométrica pois este não estava presente nos resultados das buscas nas ferramentas de pesquisa mencionadas. Apesar disso, as autoras avaliam o InnSciDSP como um meio importante para a construção de redes de pesquisadores sobre a DI e para promover a discussão e a produção científica sobre o tema.
} 
conjunto "São Paulo Framework of Innovation Diplomacy" com o intuito de orientar estudos acadêmicos sobre o tema da DI, além de estratégias de negócios e políticas relacionadas ao tema (INNSCIDSP, 2019b).

Contudo, fora destes espaços a produção acadêmica que dialoga com a DI ainda é escassa. Constatouse que grande parte da produção existente está insulada em entidades como o MRE e a Embrapa ou na produção fora destas instituições, isto é, trabalhos produzidos em universidades, mas realizada por funcionários que atuam na área de cooperação internacional das entidades mencionadas. Quanto ao caso do grupo RICTI, no médio e longo prazo, em pesquisas futuras, será possível identificar se este movimento de difusão, a partir do grupo, se trata de um caso isolado, sem uma maior difusão da DI na academia, ou se ocorreu a expansão para os demais âmbitos acadêmicos. Dessa forma, é plausível supor que, para possibilitar uma maior difusão da perspectiva brasileira da DI, seja necessária uma articulação mais abrangente e contínua entre as universidades e centros de pesquisa, que trabalham com a cooperação internacional e com a temática CT\&I, e os órgãos governamentais proponentes do conceito e que atuam ativamente na diplomacia.

Por fim, pesquisas futuras poderão averiguar se a DI foi adotada pela academia e se a sua implementação, como abordagem para uma política de inserção internacional da CT\&I brasileira, foi ampliada e executada para uma diplomacia da CT\&I que considere as capacidades no Brasil e sua posição no sistema internacional. Ademais, caso a DI seja empreendida, será útil a avaliação da sua execução e dos atores envolvidos no processo.

\section{REFERÊNCIAS}

ACUTO, Michele; KALTOFEN, Carolin. Rebalancing the Encounter between Science Diplomacy and International Relations Theory. Global Policy. V. 9, n. 3, p. 8-14, Nov. 2018a.

ACUTO, Michele; KALTOFEN, Carolin. Science Diplomacy: Introduction to a Boundary Problem. Global Policy, v. 9, n. 3, p. 15-22, Nov. 2018b.

AMERICAN ASSOCIATION FOR THE ADVANCEMENT OF SCIENCE (AAAS). 2019. Disponível em: http://www.sciencediplomacy.org/ Acesso em: 25 Jul. 2019.

ANUNCIATO, R. O. "A atuação da EMBRAPA no Projeto Estruturante para o COTTON-4: a influência da Cooperação Sul-Sul na Política Externa Brasileira”. In: SEMINÁRIO BRASILEIRO DE ESTUDOS ESTRATÉGICOS INTERNACIONAIS (SEBREEI) - O Atlântico Sul como Eixo da Inserção Internacional do Brasil. 21 a 23 de Maio, Porto Alegre/RS, Brasil, 2013.

ANUNCIATO, Renata Oliveira. Política externa brasileira e a atuação da Embrapa no caso do Cotton-4. 2014. 83 f. Dissertação (Mestrado em Ciência Política) -Universidade Federal do Rio Grande do Sul, Porto Alegre, 2014.

ARANDA, Jorge Eduardo Ferreira Silva. Diplomacia científica: das boas práticas internacionais a um modelo nacional ótimo. $101 \mathrm{f}$. Dissertação (Mestrado em Relações Internacionais)-Universidade de Lisboa, Lisboa, 2017. Disponível em: https://www.repository.utl.pt/bitstream/10400.5/14661/1/Tese\%20JA\%20pdf.pdf Acesso em 27 Jul. 2019.

ARROZ, Sónia, MENDONÇA, Sandro. Diplomacia de ciência: razões, justificações e abordagens na intersecção da investigação e internacionalização. Parcerias Estratégicas. Brasília-DF, v. 21, n. 42, p. 117-136, jan-jun

2016.

Disponível

em: 
http://seer.cgee.org.br/index.php/parcerias_estrategicas/article/viewFile/813/743 Acesso em: 27 Mai. 2019.

BRASIL. Ministério das Relações Exteriores. Programa de Diplomacia da Inovação. 2019. Disponível em: http://www.itamaraty.gov.br/pt-BR/politica-externa/ciencia-tecnologia-e-inovacao/124programa-de-diplomacia-da-inovacao Acesso em: 27 Jul. 2019.

CARLSNAES, Walter; THOMAS, Risse; SIMMONS, Beth. Handbook of International Relations. Londres: Sage Publications, 2000.

CERVO, Amado. Socializando o desenvolvimento: uma história da cooperação técnica internacional do Brasil. Brasília. Revista Brasileira de Política Internacional, v. 37, n.1, p.37-63, 1994.

CRESTANA, Sílvio. Relatório do seminário preparatório Inserção da CT\&I nos fóruns internacionais. Parcerias estratégicas, v. 15, n. 31, parte 1. Brasília: Centro de Gestão e Estudos Estratégicos, 2010.

CRUZ JUNIOR, Ademar. Relatório da sessão Diplomacia da inovação. Parcerias estratégicas, v. 15, n. 31, parte 1, Brasília: Centro de Gestão e Estudos Estratégicos. 2010.

DAVIS, Lloyd; PATMAN, Robert. Science diplomacy: new day or false dawn? Singapore: World Scientific, 2015.

BALSADI, Otavio V.; NASCIMENTO, Petula P. Governança global. In: DINIZ, Fábio H.; STUCHI, Júlia F.; NASCIMENTO, Petula. P.; BORBA, Marcos F. S. (Ed.). Paz, justiça e instituições eficazes: contribuições da Embrapa. Cap. 6, p. 57-62. Brasília, DF: Embrapa, 2018. E-book.

FEDOROFF, Nina V. Making Science Diplomacy More Effective. Testimony Before the House Science Subcommittee on Research and Science Education. Hearing on Science Diplomacy. USA, April 2, 2008. Disponível em: https://2001-2009.state.gov/g/stas/2008/105286.htm. Acesso em: 20 Jul. 2019.

FÄHNRICH, Birte. Science diplomacy: Investigating the perspective of scholars on politics-science collaboration in international affairs. Public Understanding of Science. V. 26, n. 6, p. 688-703, 2017.

FAPESP, Agência. Escola São Paulo de Ciência Avançada em Diplomacia Científica e Diplomacia da Inovação. 2019. Disponível em: http://agencia.fapesp.br/escola-sao-paulo-de-ciencia-avancadaem-diplomacia-cientifica-e-diplomacia-da-inovacao/30363/. Acesso em: 09 maio 2020.

FERENHOF, Helio Aisenberg; FERNANDES, Roberto Fabiano. Desmitificando a Revisão de Literatura como Base para Redação Científica: método SSF. Revista ACB: Biblioteconomia em Santa Catarina, Florianópolis, v. 21, n. 3, p.550-563, ago. 2016.

INNSCIDSP. About | InnSciDSP. 2019a. Disponível em: https://innscidsp.com/about/. Acesso em: 09 maio 2020.

INNSCIDSP. São Paulo Framework of Innovation Diplomacy. 2019b. Disponível em: https://innscidsp.com/sao-paulo-framework-of-innovation-diplomacy/. Acesso em: 09 maio 2020.

LEITE, Iara; GAYARD, Nicole. Quatro abordagens sobre a interação entre cientistas e Estados nas relações internacionais. R:I, n. 62, jun. 2019 (no prelo)

NYE, Joseph S. O Futuro do Poder. São Paulo: Benvirá, 2012.

POMPEI, Luciano de Melo. Descritores ou palavras-chave nas bases de dados de artigos científicos. Editorial. Femina, v. 38, n. 5, Maio 2010. 
RESEARCH AND INFORMATION SYSTEM FOR DEVELOPING COUNTRIES (RIS). 2019. Disponível em: www.ris.org.in Acesso em: 02 Jul. 2019.

ROYAL SOCIETY. New frontiers in science diplomacy: navigating the changing balance of power. RS Policy document, Jan. 2010. London: the Royal Society, 2010.

SKOLNIKOFF, Eugene B. The Elusive Transformation: Science, Technology, and the Evolution of International Politics. Princeton: Princeton University Press, 1993.

THE COUNCIL OF FINNISH ACADEMIES. 2019. Disponível em: https://www.academies.fi/en/sciencediplomacy-selected-literature/ Acesso em: 27 jul. 2019

THE WORLD ACADEMY OF SCIENCES (TWAS). 2019. Disponível em: https://twas.org/science-diplomacy Acesso em: 27 jul. 2019.

TUREKIAN, Vaughan. The Evolution of Science Diplomacy. Global Policy, v. 9, n. 3, Nov. 2018. Disponível em: https://onlinelibrary.wiley.com/doi/epdf/10.1111/1758-5899.12622 acesso em: 02 Jul. 2019

UNDP - United Nations Development Programme. The Buenos Aires Plan of Action for Promoting and Implementing Technical Co-operation among Developing Countries. New York: 1978.

VIGEVANI, Tullo; CEPALUNI, Gabriel. A política externa de Lula da Silva: a estratégia da autonomia pela diversificação. Contexto Internacional, [s.1.], v. 29, n. 2, p.273-335, dez. 2007.

WANG, Tom C. "The Evolution and Future of Science Diplomacy: a U.S. perspective”. In: The 50th GIST Seminar. GRIPS Innovation, Science and Technology Policy Program (GIST). 27 June, University of Tokyo, Tokyo, Japan. 2013. Disponível em: http://www3.grips.ac.jp/ gist/en/events/document/gistseminar_50.pdf Acesso em: 27 Set. 2019.

WEISS, Charles. How do science and technology affect international affairs? Minerva, v. 53, p. 411-30. 2015 


\title{
RESUMO
}

Neste artigo explora-se a difusão do conceito de "Diplomacia da Inovação" (DI) utilizado pelo Brasil para se inserir no contexto internacional de Diplomacia Científica (DC), dentro do panorama da pesquisa acadêmica de cooperação internacional em ciência, tecnologia e inovação (CT\&I). Dividido em três seções, trata na primeira sobre a origem do termo "Diplomacia Científica", sua definição e utilização como instrumento de política externa. Na segunda, apresenta a perspectiva brasileira de Diplomacia Científica, representada pelo conceito de "Diplomacia da Inovação", como proposta e via de inserção do País no contexto internacional da Diplomacia Científica. A terceira seção concentra-se na identificação e análise qualitativa e quantitativa dos artigos coletados, por meio da metodologia da análise bibliométrica, e que abordam a Diplomacia da Inovação. Por fim, é concluído que há difusão, no entanto, a pesquisa corroborou a hipótese de que a utilização do conceito de DI na academia, desconsiderando órgãos governamentais como Ministério das Relações Exteriores (MRE) e Empresa Brasileira de Pesquisa Agropecuária (Embrapa), ainda é embrionária.

Palavras-chave: Diplomacia Científica; Diplomacia da Inovação; Brasil.

\begin{abstract}
This article explores the pervasiveness of the concept of "Innovation Diplomacy" (ID) used by Brazil to insert itself in the international context of Science diplomacy (SD), within the outlook of academic research of international research in science, technology and innovation (ST\&I). Divided into three sections, the first looks to the origin of the term "Science diplomacy", its definition and use as an instrument of foreign policy. The next section, it brings forward the Brazilian perspective of Science diplomacy, represented by the concept of "Innovation Diplomacy", as proposal and way of insertion of the Country in the international context of Scientific Diplomacy. The third section focuses on the identification and qualitative and quantitative analysis of the articles collected, using the bibliometric analysis methodology, which addresses the "Innovation Diplomacy". In conclusion, the study shows that there is a level of pervasiveness. However, the research confirms the hypothesis that the use of the concept of ID in academia, disregarding governmental agencies, such as Ministry of Foreign Affairs and Brazilian Agricultural Research Corporation, it is still embryonic.
\end{abstract}

Keywords: Science Diplomacy; Innovation Diplomacy; Brazil.

COPYRIGHT:

Este é um artigo publicado em acesso aberto e distribuição sob os termos da Licença Creative Commons de Atribuição Não-Comercial CompartilhaIgual 4.0 Internacional (CC BY-NC-SA 4.0), que permite seu uso, distribuição e reprodução em qualquer meio, bem como sua transformação e criações a partir dele, desde que o autor e a fonte originais sejam creditados. Ainda, o material não pode ser usado para fins comerciais, e no caso de ser transformado, ou servir de base para outras criações, estas devem ser distribuídas sob a mesma licença que o original.

This is an open-access article distributed under the terms of a Creative Commons Attribution-NonCommercial-ShareAlike 4.0 International License (CC BY-NC-SA 4.0), which permits its use, distribution and reproduction in any medium or format, as well as to transform and build upon the material, provided that the original author and source are credited. Furthermore, the material cannot be used for commercial purposes, and in case it is transformed, or used as bases for other creations, these must be distributed under the same license as the original. 